\title{
Occurrence of Neotyphodium endophytes in perennial ryegrass (Lolium perenne) and fescue (Festuca spp.), and characterisation of selected isolates with respect to toxin production, drought and insect resistance
}

\author{
PRATHAP KUMAR HALADY SHETTY ${ }^{1}$, ANNE METTE DAHL JENSEN ${ }^{2}$, NIELS ROULUND ${ }^{3}$, BIRTE BOELT ${ }^{1}$ \\ ${ }^{I}$ Department of Genetics and Biotechnology, Danish Institute of Agricultural Sciences, Research Center Flakkebjerg Forsøgsvej 1, \\ DK 4200 Slagelse, Denmark \\ ${ }^{2}$ Center for Forest, Landscape and Planning, The Royal Veterinary and Agricultural University, Rolighedsvej 23 DK 1958, \\ Frederiksberg C, Denmark \\ ${ }^{3}$ DLF-Trifolium A/S, Post-box 19, Højerupvej 31, DK 4660, Store Heddinge, Denmark
}

\begin{abstract}
Neotyphodium endophytes infect the natural grass populations of Lolium perenne and Festuca sp. L. perenne samples were collected from 62 different locations in Denmark and were analysed for the presence of Neotyphodium lolii. In addition, Festuca spp., samples were collected from selected locations in Spain and Italy. Ergovaline and lolitrem B analysis of endophyte positive grass clones showed that there were grass clones with strains of endophytes which were not producing any of the two toxins, both the toxins in high levels or one of the two toxins in high levels and other one in only trace amounts. These valuable endophyte strains were identified, characterized and maintained. Selected endophytes in their native host are tested for their drought stress tolerance and recovery under various levels of drought stress. Endophyte-free host plants are used as control.
\end{abstract}

In addition to the parameters such as root and shoot biomass, relative water potential, electrolyte leakage, and osmotic adjustment, photosynthetic efficiency and assimilation and mobilization of fixed carbon are studied under these conditions. Metabolite production is followed at selected points in these treatment conditions. Relative performance of the high and low toxin producing strains of endophytes will be studied. In addition, performance and efficiency of nitrogen uptake by these plants under different stress conditions will also be studied. Some selected strains in their natural host will be tested for the insect resistance under the lab and green house conditions. Comparative quantitative herbivory, metabolite profile and performance under herbivore stress will be studied. 